\title{
$\begin{array}{ll}\text { Research Square } & \begin{array}{l}\text { Preprints are preliminary reports that have not undergone peer review. } \\ \text { They should not be considered conclusive, used to inform clinical practice, } \\ \text { or referenced by the media as validated information. }\end{array}\end{array}$
}

\section{On the Importance of Being Heterozygote - Effects of Rh- Genotype on the Physical and Mental Health of a Non-Clinical Population}

\author{
Jaroslav Flegr ( $\square$ flegr@cesnet.cz ) \\ Charles University in Prague \\ Lenka Príplatová \\ Charles University in Prague \\ Jana Hlaváčová \\ Charles University in Prague \\ Blanka Šebánková \\ Charles University in Prague \\ Emanuel Žđárský \\ Czech Republic \\ Sárka Kaňková \\ Charles University in Prague
}

\section{Research Article}

Keywords: Blood group, Rhesus factor, polymorphism, frequency-dependent selection, balancing selection, heterozygote advantage.

Posted Date: May 27th, 2021

DOI: https://doi.org/10.21203/rs.3.rs-541468/v1

License: (a) (i) This work is licensed under a Creative Commons Attribution 4.0 International License. Read Full License 


\section{Abstract}

Human populations, especially European, are polymorphic in the RHD gene. A significant fraction of their members carries two copies of a mutated (deleted) allele, which results in their Rh-negative blood type. Theoretically, this polymorphism should be unstable. Carriers of the less frequent allele are penalized by reduced fertility because of the immunization of Rh-negative mothers by their Rhpositive babies, which results in hemolytic disease of newborns in their subsequent progeny. For about 90 years, some form of balancing selection has been suspected to sustain this polymorphism. Several recent studies showed that the Rh-positive heterozygotes express higher viability than both types of homozygotes. However, the genotype of subjects in these studies was estimated only by indirect methods. Here we compared the physical and mental health of 178 women and 86 men who were directly tested for their Rh genotype. The results showed that Rh-positive homozygotic women had worse and Rh-positive homozygotic men better physical health than Rh-negative homozygotes; the difference between Rh-negative homozygotes and heterozygotes was not significant. Our results confirmed that health of Rh-positive heterozygotes and homozygotes differ. Therefore, any result of the comparison of subjects with Rh-positive and Rh-negative phenotype depends on the heterozygote-to-homozygote ratio in the Rhpositive sample. It is, therefore, crucial to analyze the effects of Rh-genotypes, not phenotypes in future studies.

\section{Introduction}

About $1 \%$ of native people in East Asia, $5 \%$ of those in Africa, and $16 \%$ of those in Europe have an Rh-negative blood type - they carry two copies of the mutated allele of the RHD gene and therefore lack the most dominant D epitope on the surface of their erythrocytes 1,2. Rh-positive subjects carry either one or two unmutated alleles of the gene. The main role of Rh complex is to transport $\mathrm{NH}_{3}$ or $\mathrm{CO}_{2}$ gases and their ions ${ }^{3,4}$ but the physiological role of this transport remains unknown. For a long time, the stable coexistence of two alleles of the gene has been an evolutionary riddle. Before the discovery of modern prophylaxis, carriers of the rarer phenotype, either Rh-negative women in a predominantly Rh-positive population or Rh-positive men in a predominantly Rh-negative population, expressed lower fecundity because part of their latter-born babies (Rh-positive babies born to Rh-negative mothers) died of hemolytic disease of newborns ${ }^{5,6}$.

During the past 15 years, several methods demonstrated that RHD polymorphism is sustained in the population by balancing selection, namely by the selection in favor of heterozygotes. One group of studies showed that Rh-positive heterozygotes have better reaction times than Rh-positive and negative homozygotes when latently infected by the protozoan parasite Toxoplasma gondii ${ }^{7,8}$. Currently, only about one-third of the population is infected with this parasite and the prevalence is decreasing at the rate of about $1 \%$ per year in most developed countries 9,10 . However, it is highly probable that the majority of people were infected in our recent evolutionary past. Later, an ecological study showed that frequency of heterozygotes negatively correlates with the incidence of many diseases and with morbidity of other diseases assessed based on DALY (Disability Adjusted Life Years). The study controlled for five potential confounding variables: GDP, latitude (distance from the equator), humidity, medical care expenditure per capita, and frequency of smokers ${ }^{11}$. Other evidence of the effects of Rh phenotype on human health were obtained in several cross-sectional studies. The most detailed study performed on 3,130 subjects showed that Rh-negative subjects scored significantly worse in 6 of 22 ordinal healthrelated variables than Rh-positive subjects ${ }^{12}$. The results also showed that Rh-negativity was positively associated with the incidence of 21 , and negatively with the incidence of 10 of 154 diseases under study. However, most cross-sectional studies compared the health and performance of subjects with Rh-positive and Rh-negative phenotypes and all relied on the information provided by participants of anonymous internet studies. The only exception is a recent study performed on 2539 subjects ${ }^{13}$. In this study, respondents were asked not only about their Rh phenotype but also Rh phenotype of their biological parents. This enabled the identification of a substantial part of heterozygotes - Rh-positive subjects with an Rh-negative mother or father. The study showed that Rh-positive heterozygotes have better health than Rh-negative homozygotes and also brought very strong evidence that they have better health even in comparison with Rh-positive homozygotes.

The main purpose of the present study is to confirm the effect of Rh-genotype on physical and mental health using a non-anonymous study with subjects whose Rh-genotype was determined by the direct molecular method in a laboratory. For this purpose, we analyzed the physical and mental health-related data of 178 women and 86 men, the representatives of the nonclinical Prague population, who consented to participate in the study performed at the Faculty of Science, Charles University.

\section{Materials And Methods}




\section{Participants}

An invitation to participate in a study "of the effects of genetic and environmental factors on human physiology, personality and behavior" was posted on the timeline of the Facebook page Labbunnies, an approximately 18,000-strong group of Czech and Slovak nationals willing to participate in evolutionary psychology experiments. The participants checked in for the study (for a specific minute) using a web form.

Participants came to our lab where they provided a blood sample for serologic and genetic testing, and completed a set of questionnaires. They received no remuneration for their participation, but obtained the information about their Rh genotype, toxoplasmosis seropositivity/seronegativity, and a commemorative badge. Before the blood sampling that occurred at the Faculty of Science in November 2018, the subjects were given written information about the aims and technical details of the study and were asked to sign the informed consent form.

\section{Questionnaire}

On the blood sample taking-day, the subjects were asked to fill in a short questionnaire. They were asked to estimate how many times they had had an acute illness, including an infection, in the past month and the past 6 months (ordinal variables acute illness in last month and acute illness in past 6 months), how many chronic health problems they had been treated for in the past month (chronic problems treated now), and how many other chronic health problems they suffer, including untreated problems (chronic problems all), how many kinds of drugs prescribed by a medical doctor they were currently taking, how well they felt physically on the blood sample taking-day (bad physical health today, 6-points scale 1: excellently, 6: very badly), how often they suffer from headaches (1: never, 2: exceptionally, 3: once a month, 4: once a week, 5: daily), and whether they had been diagnosed with tension headaches or migraines (0: no, 1: yes). In different questionnaires distributed electronically on another day, they were asked how often they suffer from allergies, skin disorders (nonallergic), circulatory system disorders (heart or vascular), digestive tract disorders (ulcer, pancreas, etc.), orthopedic disorders (backache, joints ache, etc.), neurological disorders, headaches (headaches 2), other physical pains, other chronic or recurrent physical problems, and how frequently they are tired. To answer all these questions, participants should use six-points scales (1: never, 2: maximally once a year, 3: several times a year, maximally once a month, 4: several times a month, maximally once a week, 5: two or more times a week, 6: daily or several times a day). They were also asked whether they suffer from metabolic disorders (diabetes etc.) (1: definitively no, 2: more likely no, 3: more likely yes, 4: definitively yes), what their blood pressure is (1: I do not know - coded as "ND", 2: very low, 3: rather low, 4: normal, 5: rather high, 6: very high), how often they are tired immediately after returning from work (or school) (1: never, 2: rarely, 3: sometimes, 4: often, 5: nearly always, 6: always), how often they are tired after several hours-travel by train, (the same scale), and how often they are tired after several hours-travel by bus, (the same scale). Besides that, they were asked how often they suffer from common infectious diseases like influenza or a similar viral or bacterial disease (1: never, 2: maximally once a year, 3: several times a year, maximally once a month, 4: several times a month, maximally once a week, 5: two or more times a week), how often they attend medical doctors (not dentist and not for prevention) (1: never, 2: maximally once a year, 3: several times a year, maximally once a month, 4: several times a month, maximally once a week, 5: two or more times a week), how many times they had used antibiotics in the last year (1: never, 2: once, 3: twice, 4: three times, 5: four times 6: five or more times), how many times they had used antibiotics in the last 3 years (the same scale), how many times they had spent more than a week in a hospital in the last year (the same scale), how many times they had spent more than a week in a hospital in the past 5 years (the same scale), and how long they expect to live (life expectancy 1: more than 99 years. 2: 90-99 years, 3: 80-90 years, 4: 70-79 years, 5: 60-69 years, 6: less than 60 years). Physical health problems score was computed as mean Z-score from these 30 physical health-related variables.

In the first questionnaire (before blood taking), participants were asked to rate how well they feel mentally today (bad mental health today, 6-points scale anchored with 1: excellent, 6 : very bad). In the following electronic questionnaires, they were asked how many specific learning disabilities (e.g. dyslexia or dysgraphia) they have, whether they suffer from phobias (anchored with 1: no, 6: yes, with many or intensive), from depression (1: never, 2 maximally once a year, 3: several times a year, maximally once a month, 4: several times a month, maximally once a week, 5 : two or more times a week, 6 : daily or several times a day), and from other mental health problems (the same scale). They were also asked whether they feel mentally bad today (anchored with 1: definitively no, 6: definitively yes), and whether they feel mentally badly usually (the same 6-point scale). Separately, participants also completed a standard NEO-PI$\mathrm{R}$ questionnaire with its neuroticism subscales anxiousness and depressiveness ${ }^{18}$. Mental health problems score was computed as a mean Z-score from these 9 mental health-related variables.

\section{Rh genotyping}

Page $3 / 12$ 
Fresh blood samples $(100 \mu \mathrm{l})$ were mixed with $200 \mu \mathrm{l} 10 \mathrm{mM}$ Tris buffer of $\mathrm{pH} 7.0$ containing $5 \mathrm{mM}$ EDTA (TE), frozen, and stored in $-20^{\circ} \mathrm{C}$. After thawing, DNA was isolated with phenol-chloroform method and resuspended in the final volume of approximately $50 \mu \mathrm{ITE}$. One $\mu \mathrm{l}$ of the sample was added to the $9 \mu \mathrm{l}$ reaction mix ( $0.1 \mu \mathrm{l} 5 \mathrm{U}$ Taq DNA polymerase (SBD, Tartu, Estland), $1 \mu \mathrm{l} 10 \times$ Taq DNA polymerase buffer, $0.6 \mu \mathrm{l} 25 \mathrm{mM} \mathrm{MgCl} 2,0.2 \mu \mathrm{l} 10 \mathrm{mM}$ dNTPs, $0.1 \mu \mathrm{l}$ primer 5' CCCAGTGACCCACATGC 3', 0.1 primer 5' CCTACATTGTGCTGCTGG $3^{\prime}$, and $7 \mu \mathrm{lddH} 20$ ), mixed and loaded to 96 -well plate, overlaid with $10 \mu \mathrm{l}$ mineral oil and amplified (forty cycles: $95^{\circ} \mathrm{C} / 30 \mathrm{sec}-56^{\circ} \mathrm{C} / 30 \mathrm{sec}-72^{\circ} \mathrm{C} / 30 \mathrm{sec}$ ). After the amplification, $0.3 \mu$ l of LCGreenPlus (Invitrogen, USA), was added to each well and the plate was analyzed on LightTyper (Roche, Switzerland), in temperatures $75-85^{\circ} \mathrm{C}$. One peek at $81^{\circ} \mathrm{C}$ was present in the profile of Rh-negative homozygotes and two peeks at $82^{\circ} \mathrm{C}$ and $83.5^{\circ} \mathrm{C}$ in the profile of Rh heterozygotes (the ratio of heights $2: 1$ ) and Rhpositive homozygotes (the ratio of heights $1: 1$ ).

\section{Statistics}

R v. 3.3.1 ${ }^{19}$ was used for all statistical tests. Associations of Rh genotype with sex were measured using a contingency table and the association of these two factors with physical health problems score and mental health problems score (which had normal distributions) was tested using ANCOVA (Type III sum of squares) with the age of subjects as covariate. Associations of Rh genotype with source health-related variables (which had mostly highly asymmetric distributions) were measured by a (nonparametric) partial Kendall correlation test ( $\mathrm{R}$ package ppcor $1.1^{20}$ ) with age as a covariate. Correction for multiple tests was done using the BenjaminiHochberg procedure with a false discovery rate pre-set to $0.20^{21}$ using the Excel sheet published by McDonald ${ }^{22}$.

Ethics. The project was approved by the Ethics Committee of the Faculty of Science, Charles University (No. 2017/08). All experiments were performed in accordance with relevant guidelines and regulations; and informed consent was obtained from all participants and/or their legal guardians.

\section{Results}

The population under study consisted of 178 women and 86 men. Men (mean age: $32.3, S D=10.3$ ) were about three years older than women (mean age: 29.1, SD = 10.3), $t=-2.45, p=0.015$, Cohen $d=0.32$. Among women, we detected $43(24.2 \%)$ Rh-negative homozygotes, 52 (29.2\%) Rh-positive homozygotes, and 83 (46.6\%) Rh-positive heterozygotes. Among men, we detected 24 (27.9\%) Rh-negative homozygotes, 23 (26.7\%) Rh-positive homozygotes, and 39 (45.3\%) Rh-positive heterozygotes (Rh genotype-sex: Chi ${ }^{2}=$ $0.466, d f=2, p=0.792)$.

The ANCOVA test with physical health problems score or mental health problems score as the dependent variable, sex and Rh genotype as factors, and age as a covariate found a significant negative association of age with physical health problems score $($ beta $=-0.172)$ and mental health problems score (beta $=-\mathbf{0 . 2 3 5}$ ), as well as a significant association of Rh genotype-sex interaction with the physical health problems score, see the Table 1. Visual inspection of Fig. 1 showed that Rh-negative homozygotes had similar physical health as Rh-positive heterozygotes, however, male Rh-positive homozygotes have the best, and female Rh-positive homozygotes the worst physical health of all six groups. The shape of the distributions also suggested that subpopulations of heterozygotic women and Rhpositive homozygotic men might be heterogenic - they could contain two distinct populations. Also, the physical health problems score of heterozygotic men might be negatively affected by a small number of outliers with very bad health. Separate ANCOVA tests showed that the association between Rh genotype and physical health problems score was significant for 178 women $\left(p=0.039\right.$, eta ${ }^{2}$ $=0.035)$ but not for less numerous (86) men $\left(p=0.429\right.$, eta $\left.{ }^{2}=0.020\right)$. The association of Rh genotype with the mental health problems score was neither significant for women $\left(p=0.225\right.$, eta $\left.{ }^{2}=0.017\right)$, nor for men $\left(p=0.795\right.$, eta $\left.{ }^{2}=0.006\right)$. 
Table 1

Effects of Rh genotype on physical and mental health measured with ANCOVA

\begin{tabular}{|lllllll|}
\hline & \multicolumn{3}{l}{ Physical health problems score } & \multicolumn{3}{l|}{ Mental health problems score } \\
& F & p & eta & F & $p$ & eta $^{2}$ \\
\hline age & 7.980 & 0.005 & 0.030 & 14.695 & 0.000 & 0.054 \\
\hline sex & 3.565 & 0.060 & 0.014 & 0.071 & 0.789 & 0.000 \\
\hline Rh genotype & 0.133 & 0.876 & 0.001 & 1.189 & 0.306 & 0.009 \\
\hline sex-Rh genotype & 3.299 & 0.038 & 0.025 & 0.078 & 0.925 & 0.001 \\
\hline
\end{tabular}

Post hoc ANCOVA tests with physical health problems score as the dependent variable performed separately for women and men showed significantly worse health in Rh-positive female homozygotes than Rh-negative female homozygotes $\left(p=0.026\right.$, eta ${ }^{2}=0.053$, beta $=-0.225)$ and Rh-positive female heterozygotes $\left(p=0.047\right.$, eta ${ }^{2}=0.030$, beta $\left.=0.170\right)$. No other difference between Rh genotypes was significant either for physical or mental health problems score.

To see which specific health problems were responsible for the observed effect of the Rh genotype, we performed a partial Kendall correlation test controlled for age for all source variables originally used for computing physical and mental health problems scores. Table 2 shows that, generally, heterozygotes have better health than Rh-positive homozygotes. In women, Rh-negative homozygotes had better health than Rh-positive homozygotes and often also than heterozygotes while the opposite is true for men. However, the general pattern also had some exceptions. For example, heterozygotic men scored better in most parameters of physical and mental health than Rh-positive homozygotes but they reported suffering from more chronic problems and consuming more medical drugs currently.

To be able to compare our results with those already published, we pooled Rh-positive homozygotes and heterozygotes and repeated the analyses with the binary variable Rh-positivity instead of nominal variable Rh genotype (Fig. 2). ANCOVA tests showed no significant effect of Rh phenotype or Rh phenotype-sex interaction on the scores of mental or physical health problems (physical health-sex-Rh: $p=0.103$, eta ${ }^{2}=0.010$; mental health-sex-Rh phenotype: $p=0.912$, eta ${ }^{2}<0.0001$ ). However, partial Kendall analyses showed several significant effects of Rh phenotype on the source of physical and mental health-related variables. Generally, Rhpositive women reported worse and Rh-positive men better health than their Rh-negative peers (Table 2). 
Table 2

Effects of Rh genotype and phenotype on physical and mental health problems scores and their source variables

\begin{tabular}{|c|c|c|c|c|c|c|c|c|c|c|c|c|}
\hline & All & & & & Women & & & & Men & & & \\
\hline & $+-/++$ & $+-/-$ & $++/-$ & $\mathrm{p}+/ \mathrm{p}-$ & $+-/++$ & $+-/-$ & $++/-$ & $p+/ p-$ & $+-/++$ & $+/-$ & $++/-$ & $p+/ p-$ \\
\hline $\begin{array}{l}\text { physical health } \\
\text { problems score }\end{array}$ & -0.080 & 0.003 & 0.086 & 0.031 & -0.129 & 0.059 & 0.194 & 0.098 & 0.004 & -0.158 & -0.209 & -0.156 \\
\hline $\begin{array}{l}\text { mental health } \\
\text { problems score }\end{array}$ & -0.123 & -0.027 & 0.095 & 0.017 & -0.122 & -0.008 & 0.117 & 0.035 & -0.120 & -0.079 & 0.045 & -0.031 \\
\hline $\begin{array}{l}\text { acute illness in } \\
\text { the last month }\end{array}$ & 0.001 & 0.073 & 0.076 & 0.064 & 0.025 & 0.078 & 0.058 & 0.062 & -0.052 & 0.049 & 0.113 & 0.067 \\
\hline $\begin{array}{l}\text { acute illness in } \\
\text { the past } 6 \\
\text { months }\end{array}$ & -0.070 & -0.023 & 0.045 & 0.003 & 0.019 & 0.055 & 0.047 & 0.046 & -0.295 & -0.218 & 0.072 & -0.097 \\
\hline $\begin{array}{l}\text { chronic } \\
\text { problems } \\
\text { treated now }\end{array}$ & 0.011 & 0.115 & 0.104 & 0.097 & -0.058 & 0.108 & 0.161 & 0.110 & 0.175 & 0.138 & -0.046 & 0.070 \\
\hline $\begin{array}{l}\text { chronic } \\
\text { problems all }\end{array}$ & 0.001 & 0.056 & 0.061 & 0.052 & -0.067 & 0.031 & 0.094 & 0.048 & 0.160 & 0.102 & -0.030 & 0.052 \\
\hline $\begin{array}{l}\text { drugs } \\
\text { prescribed }\end{array}$ & 0.055 & 0.080 & 0.043 & 0.057 & -0.017 & 0.107 & 0.132 & 0.097 & 0.217 & 0.041 & -0.145 & -0.020 \\
\hline $\begin{array}{l}\text { bad physical } \\
\text { health today }\end{array}$ & -0.043 & -0.081 & -0.058 & -0.063 & -0.111 & -0.086 & 0.021 & -0.040 & 0.103 & -0.061 & -0.214 & -0.102 \\
\hline headaches & -0.059 & 0.052 & 0.111 & 0.066 & -0.127 & 0.068 & 0.190 & 0.102 & 0.074 & -0.032 & -0.106 & -0.054 \\
\hline migraines & -0.033 & 0.078 & 0.115 & 0.078 & -0.100 & 0.084 & 0.186 & 0.104 & 0.161 & 0.068 & -0.147 & 0.014 \\
\hline life expectancy & 0.062 & -0.028 & -0.115 & -0.052 & 0.060 & 0.059 & -0.013 & 0.031 & 0.083 & -0.173 & -0.344 & -0.217 \\
\hline allergies & 0.038 & 0.003 & -0.022 & -0.007 & 0.002 & 0.018 & 0.035 & 0.022 & 0.129 & -0.012 & -0.136 & -0.056 \\
\hline skin disorders & -0.131 & -0.072 & 0.053 & -0.022 & -0.167 & -0.119 & 0.054 & -0.048 & -0.036 & 0.039 & 0.049 & 0.038 \\
\hline $\begin{array}{l}\text { circulatory } \\
\text { system } \\
\text { disorders }\end{array}$ & -0.018 & 0.013 & 0.027 & 0.017 & -0.064 & -0.034 & 0.040 & -0.002 & 0.071 & 0.074 & 0.000 & 0.050 \\
\hline blood pressure & 0.001 & -0.082 & -0.075 & -0.070 & -0.048 & -0.049 & -0.009 & -0.028 & 0.131 & -0.146 & -0.191 & -0.150 \\
\hline $\begin{array}{l}\text { digestive tract } \\
\text { disorders }\end{array}$ & 0.051 & 0.062 & -0.003 & 0.037 & 0.027 & 0.091 & 0.051 & 0.070 & 0.106 & -0.045 & -0.164 & -0.080 \\
\hline $\begin{array}{l}\text { metabolic } \\
\text { disorders }\end{array}$ & 0.060 & 0.089 & 0.026 & 0.060 & 0.064 & 0.108 & 0.048 & 0.076 & 0.024 & 0.011 & -0.036 & -0.003 \\
\hline $\begin{array}{l}\text { orthopedic } \\
\text { disorders }\end{array}$ & -0.075 & 0.060 & 0.142 & 0.081 & -0.131 & 0.085 & 0.222 & 0.119 & 0.024 & -0.068 & -0.062 & -0.056 \\
\hline $\begin{array}{l}\text { neurological } \\
\text { disorders }\end{array}$ & -0.112 & -0.006 & 0.097 & 0.031 & -0.155 & 0.020 & 0.177 & 0.070 & -0.019 & -0.050 & -0.064 & -0.051 \\
\hline headaches 2 & -0.099 & 0.066 & 0.186 & 0.097 & -0.098 & 0.140 & 0.249 & 0.159 & -0.121 & -0.128 & 0.041 & -0.059 \\
\hline physical pains & -0.132 & -0.005 & 0.126 & 0.038 & -0.177 & -0.006 & 0.171 & 0.050 & -0.080 & -0.034 & 0.072 & 0.007 \\
\hline $\begin{array}{l}\text { chronic } \\
\text { physical } \\
\text { problems }\end{array}$ & -0.205 & -0.102 & 0.113 & -0.020 & -0.306 & -0.077 & 0.249 & 0.038 & 0.008 & -0.160 & -0.193 & -0.161 \\
\hline tired & -0.073 & -0.048 & 0.020 & -0.020 & -0.073 & -0.010 & 0.060 & 0.015 & -0.044 & -0.159 & -0.083 & -0.118 \\
\hline tired after work & -0.134 & -0.094 & 0.040 & -0.041 & -0.170 & -0.112 & 0.063 & -0.043 & -0.054 & -0.074 & -0.014 & -0.047 \\
\hline tired after train & -0.052 & 0.045 & 0.080 & 0.052 & -0.051 & 0.072 & 0.111 & 0.079 & -0.040 & -0.027 & 0.017 & -0.003 \\
\hline
\end{tabular}




\begin{tabular}{|c|c|c|c|c|c|c|c|c|c|c|c|c|}
\hline & All & & & & Women & & & & Men & & & \\
\hline tired after bus & -0.171 & 0.001 & 0.155 & 0.051 & -0.189 & -0.039 & 0.146 & 0.027 & -0.106 & 0.053 & 0.122 & 0.076 \\
\hline $\begin{array}{l}\text { common } \\
\text { infectious } \\
\text { diseases }\end{array}$ & 0.098 & -0.049 & -0.141 & -0.076 & 0.091 & 0.098 & 0.013 & 0.059 & 0.106 & -0.357 & -0.429 & -0.348 \\
\hline $\begin{array}{l}\text { medical } \\
\text { doctors }\end{array}$ & -0.074 & 0.026 & 0.099 & 0.048 & -0.106 & 0.062 & 0.171 & 0.091 & 0.013 & -0.056 & -0.062 & -0.047 \\
\hline $\begin{array}{l}\text { antibiotics in } \\
\text { the last year }\end{array}$ & 0.053 & 0.074 & 0.052 & 0.058 & 0.045 & 0.146 & 0.143 & 0.127 & 0.068 & -0.090 & -0.140 & -0.102 \\
\hline $\begin{array}{l}\text { antibiotics in } \\
\text { the last } 3 \text { years }\end{array}$ & -0.014 & 0.012 & 0.034 & 0.017 & -0.039 & 0.061 & 0.129 & 0.076 & 0.060 & -0.093 & -0.158 & -0.106 \\
\hline $\begin{array}{l}\text { hospital in the } \\
\text { last year }\end{array}$ & 0.119 & 0.116 & -0.017 & 0.073 & 0.112 & 0.095 & -0.025 & 0.055 & 0.121 & 0.142 & NA & 0.100 \\
\hline $\begin{array}{l}\text { hospital in the } \\
\text { past } 5 \text { years }\end{array}$ & -0.003 & 0.140 & 0.152 & 0.125 & -0.020 & 0.127 & 0.162 & 0.119 & 0.031 & 0.161 & 0.136 & 0.138 \\
\hline $\begin{array}{l}\text { bad mental } \\
\text { health today }\end{array}$ & -0.119 & -0.028 & 0.080 & 0.011 & -0.163 & -0.007 & 0.161 & 0.050 & -0.017 & -0.084 & -0.102 & -0.079 \\
\hline $\begin{array}{l}\text { learning } \\
\text { disabilities }\end{array}$ & -0.005 & 0.050 & 0.052 & 0.045 & 0.001 & 0.085 & 0.083 & 0.073 & -0.020 & 0.016 & 0.037 & 0.021 \\
\hline $\begin{array}{l}\text { mentally bad } \\
\text { today }\end{array}$ & -0.041 & -0.026 & 0.017 & -0.010 & -0.079 & -0.045 & 0.044 & -0.012 & 0.032 & 0.016 & -0.038 & -0.002 \\
\hline $\begin{array}{l}\text { mentally bad } \\
\text { usually }\end{array}$ & -0.178 & -0.093 & 0.085 & -0.025 & -0.167 & -0.074 & 0.104 & -0.007 & -0.198 & -0.125 & 0.063 & -0.053 \\
\hline anxiousness & -0.016 & -0.020 & 0.002 & -0.010 & -0.024 & -0.026 & 0.006 & -0.011 & -0.010 & -0.031 & -0.072 & -0.045 \\
\hline depressiveness & -0.097 & -0.045 & 0.048 & -0.010 & -0.077 & -0.066 & 0.006 & -0.034 & -0.133 & -0.012 & 0.114 & 0.032 \\
\hline phobiaes & 0.039 & -0.009 & -0.057 & -0.023 & 0.037 & 0.001 & -0.041 & -0.011 & 0.011 & -0.070 & -0.107 & -0.074 \\
\hline depressions & -0.132 & -0.057 & 0.064 & -0.010 & -0.099 & 0.016 & 0.106 & 0.045 & -0.202 & -0.211 & -0.002 & -0.122 \\
\hline $\begin{array}{l}\text { other mental } \\
\text { health } \\
\text { problems }\end{array}$ & -0.106 & 0.074 & 0.183 & 0.101 & -0.080 & 0.101 & 0.182 & 0.114 & -0.168 & 0.018 & 0.196 & 0.077 \\
\hline
\end{tabular}

This table shows the direction and strength of particular effects (Taus) measured with a nonparametric partial Kendall correlation test controlled for age. The,,,$+++-- p$-, and $p+$ at the column headings denote Rh-positive homozygotes, Rh-positive heterozygotes, Rhnegative homozygotes, Rh-negative and Rh-positive subjects, respectively. Negative Tau means that the genotype or phenotype that is on the left from the slash has a better health parameter than the genotype that is on the right from the slash. Significant Taus $(p<0.05)$ are printed in bold. The results are presented without any correction for multiple tests, however, most of the significant associations remained significant even after such correction with the Benjamini-Hochberg procedure.

\section{Discussion}

Our results suggest the effect of RhD genotype-sex interaction on physical health. Generally, Rh-positive homozygotic women reported worse physical health than both Rh-negative and heterozygotic women, while Rh-negative men reported worse physical health than Rhpositive homozygotic and heterozygotic men. Similar yet nonsignificant trends in the same direction are present when the mental health of subjects with Rh-negative and Rh-positive phenotype is compared. Better health of heterozygotes than homozygotes was expected a priori based on the theory and already published data ${ }^{13}$. Therefore, more sensitive one-sided tests should be used in the confirmatory part of the study. Result of this test, the effect of Rh-sex interaction on physical health, remained significant $(p=0.019)$ after the correction for multiple (here two) tests. 
Detailed analyses showed that Rh-positive homozygote women reported being more often tired, more often spending more than seven days in a hospital in the past 5 years, having more frequent chronic health problems, physical pain, headaches, migraines, orthopedic problems, neurological problems, attending medical doctors more often, taking more antibiotics in the last year, and having "other mental health problems" more often than Rh-negative homozygote women. In contrast, Rh-positive homozygote men reported better physical condition at the time of blood sample-taking, a higher life expectancy, and less frequent common infectious diseases than Rhnegative homozygote men. The number of significant effects was lower in men than in women, probably because of the much lower number of men than women in our sample (86 vs 178), however, the effects were usually stronger than in women. For example, a partial Kendall's Tau - 0.429 for common infectious diseases was equivalent to $R^{2} 0.49$, which means that Rh genotype was responsible for nearly $50 \%$ of the variability in the frequencies of common infectious diseases in the sample of male Rh-positive and negative homozygotes.

A comparison of female Rh-positive homozygotes and heterozygotes showed that heterozygotes had fewer headaches, skin disorders, orthopedic disorders, neurological disorders, suffered less physical pains, less chronic physical problems, are less frequently tired, and feel in better mental health conditions usually, as well as at the time of blood sample-taking. The same comparison for male homozygotes and heterozygotes showed that heterozygotes had had fewer acute illnesses in the past 6 months, feel usually in better mental conditions, and especially feel less depressed. At the same time, heterozygotes reported to be treated for chronic problems more often - which corresponded with taking more prescribed drugs at the time of blood sample-taking.

Heterozygotic men reported less frequent acute disorders, especially common infectious diseases, and less frequent or less serious depression than Rh-negative men. Paradoxically, heterozygotic women reported more frequent headaches, consuming more antibiotics, and staying for more than one week in the hospital more often than Rh-negative women. A higher frequency of headaches in (healthier) heterozygotes was already described in the previous study ${ }^{13}$.

A comparison of women with Rh-positive and Rh-negative phenotype showed worse health of the former. Rh-positive women reported more chronic problems, more headaches, migraines, orthopedic disorders, more frequent use of antibiotics in the past year, more frequently spending at least seven days in a hospital in the past five years, and more intensive "other" mental health problems (other than depression, anxiousness, phobias). Rh-positive men reported longer life expectancy, less frequent chronic physical health problems, and less frequent common infectious diseases. In fact, Rh-positive men scored non-significantly better in nearly all other health-related variables (except frequency of hospitalization) but most of these (sometimes relatively strong) associations were nonsignificant because of the low number of male participants in the study.

Present results can be compared with those of the recent study based on data from 2,539 respondents of an electronic questionnaire ( $23 \%$ Rh negative) ${ }^{13}$. In this study, a subpopulation of Rh-positive heterozygotes was identified based on their Rh-phenotype (positive) and Rh-phenotype of their biological parents (either father or mother Rh-negative). This design did not allow comparing Rh-positive homozygotes with the other two groups because part of heterozygotes did not report an Rh-negative parent and these subjects finished in the same group as homozygotes. Moreover, the spectrum of health-related variables under the above-mentioned study was different and far narrower in comparison with the present study.

Results of the internet study ${ }^{13}$ showed that heterozygotes have better health than both types of homozygotes. In contrast to the present study, subjects with Rh-positive phenotype (especially men) expressed better health than those with Rh-negative phenotype, which is in agreement with the results of other studies. The internet study found a stronger effect of Rh phenotype on mental health than on physical health; in the current study, the effect of genotype on mental health was not significant. Besides, the previous study observed worse physical health in Rh-positive than in Rh-negative homozygotes both in men and women (not only in women as it was in the current study). Nevertheless, it must be remembered that the current study was performed on just 86 men ( 23 Rh-positive and 23 negative homozygotes) compared to 502 men in the previous study. Therefore, the absence of certain significant effects could be the result of the smaller population sample analyzed in the current study.

Another recent internet study performed on a sample of 5527 participants ( $24 \%$ Rh negative) compared only the physical and mental health of subjects with Rh-positive and Rh-negative phenotype ${ }^{14}$. This internet study found worse health in Rh-positive women and better health in Rh-positive men in comparison to corresponding Rh-negative controls.

All available data about the performance of Rh-positive homozygotes and heterozygotes ${ }^{7,8,13}$ and the present study therefore suggest that Rh-positive heterozygotes have better and Rh-positive homozygotes have worse heath than Rh-negative subjects. Consequently, it 
could be argued that the results of a study depend on the heterozygote-to-homozygote ratio among Rh-positive subjects. This ratio increases with the increasing prevalence of Rh-minus allele in the population under study, which depends not only on its prevalence in a general population but probably also on the auto-selection of the participants of the study - see the over-representation of Rhnegative subjects in the studies discussed below.

Another biological variable that should be taken into consideration is the prevalence of latent toxoplasmosis in studied population sample. This prevalence varies approximately from 10 to $70 \%$ among various countries, depending on environmental conditions (especially moisture), eating and other cultural habits, and hygienic standards ${ }^{9,10}$. It also strongly varies in relation to urbanization and increases with the age of subjects ${ }^{15,16}$. It has been known for a long time that the effects of Rh-genotype are modulated by toxoplasmosis ${ }^{7,8}$. For example, among Toxoplasma-free subjects, those who are Rh-negative have extremely good reaction times. However, after Toxoplasma infection, the reaction times of Rh-negatives strongly deteriorate. This results in the observation that Rhnegative Toxoplasma-infected individuals express the worst reaction times from all subjects. In contrast with that, the reaction times of Rh-positive homozygotes impair only slightly while the reaction times of Rh-positive heterozygotes improve. It has been suggested that this might show that the natural status of our relatively recent ancestors was actually being Toxoplasma-infected with our physiology tuned up to this status ${ }^{13}$. If we continue in this line of thinking, the spreading of the allele for Rh-negativity in Europe could have been related to the relative scarcity of toxoplasmosis in Europe before the advent of the domestic cat - the only important definitive host of Toxoplasma in Holocene Europe 7,17 . It is therefore desirable to control or this variable in future studies. The prevalence of latent toxoplasmosis in Czech residents of middle age is relatively high, especially in women ${ }^{16}$. The presence of about one-third of Toxoplasma-infected subjects therefore might explain some heterogeneity in the distribution of the health problems score observed in our data (Fig. 1). In future (large-scale) studies, analyses should be done separately for Toxoplasma-free and Toxoplasma-infected subjects.

\section{The strengths and limitations of the study}

The main strength of the present study is that, for the first time, the subjects were genotyped by a molecular method. In previous studies, either the genotypes were estimated based on the phenotype of parents, or only the effects of Rh phenotypes, not Rh genotypes, were studied. Another important advantage is that the Rh phenotypes/genotypes were estimated in the course of a study and not self-reported by the participants of the study.

The main limitation of the study is that subjects reported their health problems themselves. It is clear that some people might misreport their health problems. However, there is no reason to expect that Rh-positive heterozygotes and homozygotes (mis)reported their problems differently unless they really differ in their health status. It is important to remember that participants were not aware of their $\mathrm{RhD}$ genotype at the time of filling the questionnaire. Another limitation of the present study is that participants have been self-selected and therefore probably do not represent a typical Czech population. The observed higher prevalence of Rh-negative subjects among the participants (24.2\% in women and $27.2 \%$ in men) than in the general Czech population (16\%) (a phenomenon reported also in all previous Czech studies on volunteers, reviewed in ${ }^{13}$ ) suggests that Rh-negative subjects have a higher willingness to participate in unpaid scientific studies.

\section{Conclusions}

For the first time, we have confirmed the effect of Rh genotype on human viability (health) in the sample of subjects directly Rhgenotyped by a molecular method. We demonstrated that the effect is modulated by the sex of the subjects - Rh-positive women had worse and Rh-positive men had better physical health than Rh-negative homozygotes. These results strongly suggest that the performance of Rh-positive subjects depends on heterozygote/homozygote ratio, which could strongly vary depending on the frequency of the Rh-negative allele in the general population and the method of recruitment of participants to the study. This strongly underlines that the performance and health of subjects with different Rh-genotypes, not just phenotypes, should be compared in future studies.

\section{Declarations}

Data availability. All relevant data are available at Figshare - 10.6084/m9.figshare.14235884 (Flegr, 2021).

\section{Acknowledgements}

Page $9 / 12$ 
We would like to thank Lincoln Cline, for final revisions of our text. This work was supported by Czech Science Foundation (grant No. 18-13692S) and Charles University (Research Centre program No. 204056).

\section{Author contributions}

JF and ŠK designed the study, LP, JH, BŠ collected the data, EŽ and JH genotyped the samples, all authors participated on writing the manuscript and all authors gave final approval for publication.

\section{Additional Information}

The authors declare no competing interests.

Conflicts of interest: Authors have no conflict of interests.

\section{References}

1. Wagner, F. F. \& Flegel, W. A. RHD gene deletion occurred in the Rhesus box. Blood. 95, 3662-3668 (2000).

2. Flegel, W. A. Molecular genetics and clinical applications for RH. Transfus. Apher. Sci. 44, 81-91 (2011).

3. Kustu, S. \& Inwood, W. Biological gas channels for NH3 and CO2: evidence that Rh (rhesus) proteins are $\mathrm{CO} 2$ channels. Transfus. Clin. Biol. 13, 103-110 (2006).

4. Nakhoul, N. L. \& Hamm, L. L. Characteristics of mammalian Rh glycoproteins (SLC42 transporters) and their role in acid-base transport. Mol. Aspects Med. 34, 629-637 https://doi.org/10.1016/j.mam.2012.05.013 (2013).

5. Haldane, J. B. S. Selection against heterozygosis in Man. Eugenics. 11, 333-340 (1942).

6. Fisher, R. A., Race, R. R. \& Taylor, G. L. Mutation and the Rhesus reaction. Nature. 153, 106-106 (1944).

7. Novotná, M. et al. Toxoplasma and reaction time: Role of toxoplasmosis in the origin, preservation and geographical distribution of Rh blood group polymorphism. Parasitology. 135, 1253-1261 (2008).

8. Flegr, J., Novotná, M., Lindová, J. \& Havlíček, J. Neurophysiological effect of the Rh factor. Protective role of the RhD molecule against Toxoplasma-induced impairment of reaction times in women. Neuroendocrinol. Lett. 29, 475-481 (2008).

9. Pappas, G., Roussos, N. \& Falagas, M. E. Toxoplasmosis snapshots: Global status of Toxoplasma gondii seroprevalence and implications for pregnancy and congenital toxoplasmosis. Int. J. Parasitol. 39, 1385-1394 (2009).

10. Tenter, A. M., Heckeroth, A. R. \& Weiss, L. M. Toxoplasma gondii: from animals to humans. Int. J. Parasitol. 30, 1217-1258 (2000).

11. Flegr, J. Heterozygote advantage probably maintains Rhesus factor blood group polymorphism: Ecological regression study. PLoS ONE. 11, https://doi.org/10.1371/journal.pone.0147955 (2016).

12. Flegr, J., Hoffmann, R. \& Dammann, M. Worse health status and higher incidence of health disorders in Rhesus negative subjects. PLOS ONE. 10, https://doi.org/10.1371/journal.pone.0141362 (2015).

13. Flegr, J., Toman, J., Hula, M. \& Kankova, S. The role of balancing selection in maintaining human RhD blood group polymorphism: A preregistered cross-sectional study. J. Evol. Biol. https://doi.org/10.1111/jeb.13745 (2020).

14. Flegr, J., Kuba, R. \& Kopecký, R. Rhesus-minus phenotype as a predictor of sexual desire and behavior, wellbeing, mental health, and fecundity. PLOS ONE. 15, e0236134 https://doi.org/10.1371/journal.pone.0236134 (2020).

15. Kolbeková, P., Kourbatova, E., Novotná, M., Kodym, P. \& Flegr, J. New and old risk-factors for Toxoplasma gondii infection: prospective cross-sectional study among military personnel in the Czech Republic. Clin. Microbiol. Infec. 13, 1012-1017 (2007).

16. Flegr, J. Predictors of Toxoplasma gondii infection in Czech and Slovak populations: the possible role of cat-related injuries and risky sexual behavior in the parasite transmission. Epidemiol. Infect. 145, 1351-1362 https://doi.org/10.1017/s095026881700019x (2017).

17. Torrey, E. F. \& Yolken, R. H. Could schizophrenia be a viral zoonosis transmitted from house cats. Schizophr. Bull. 21, 167-171 (1995).

18. Costa, P. T. \& McCrae, R. R. Revised NEO PersonalityInventory (NEO PI-R) and NEO Five-Factor Inventory (NEOFFI) professional manual (Psychological Assessment Resources, 1992).

19. R Core Team. (Vienna. Austria, 2018). 
20. Kim, S. \& ppcor An R package for a fast calculation to semi-partial correlation coefficients. Commun. Stat. Appl. Methods. 22, 665674 https://doi.org/10.5351/CSAM.2015.22.6.665 (2015).

21. Benjamini, Y. \& Hochberg, Y. Controlling the false discovery rate: A practical and powerful approach to multiple testing. J. Roy. Stat. Soc. B Met. 57, 289-300 (1995).

22. McDonald, J. H. Handbook of Biological Statistics 3rd edn (Sparky House Publishing, 2014).

\section{Figures}

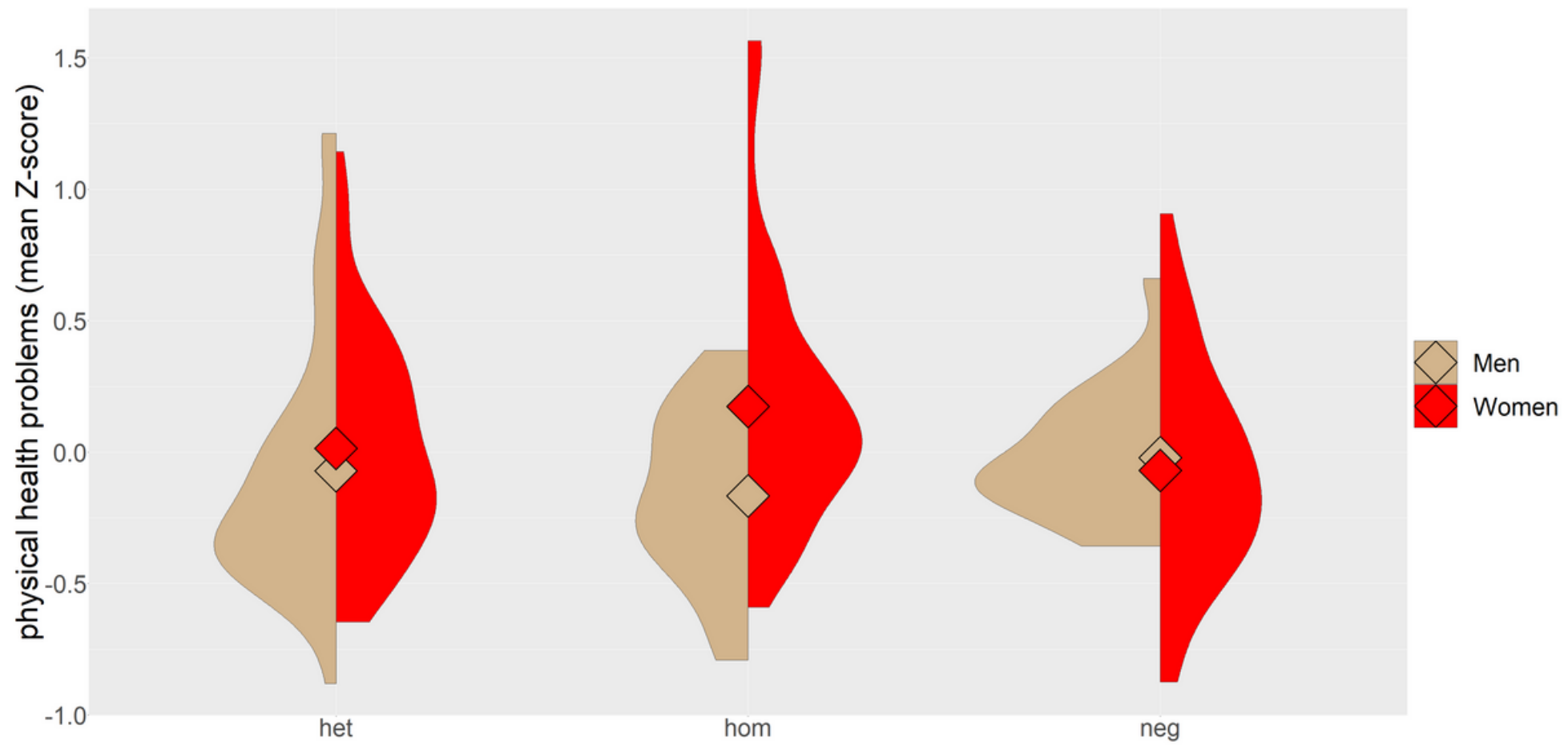

\section{Figure 1}

Physical health problems score of men and women with different Rh genotype The figure shows the means and the distribution computed as the kernel probability density for male and female heterozygotes (het), Rh-positive homozygotes (hom), and Rh-negative homozygotes (neg). 

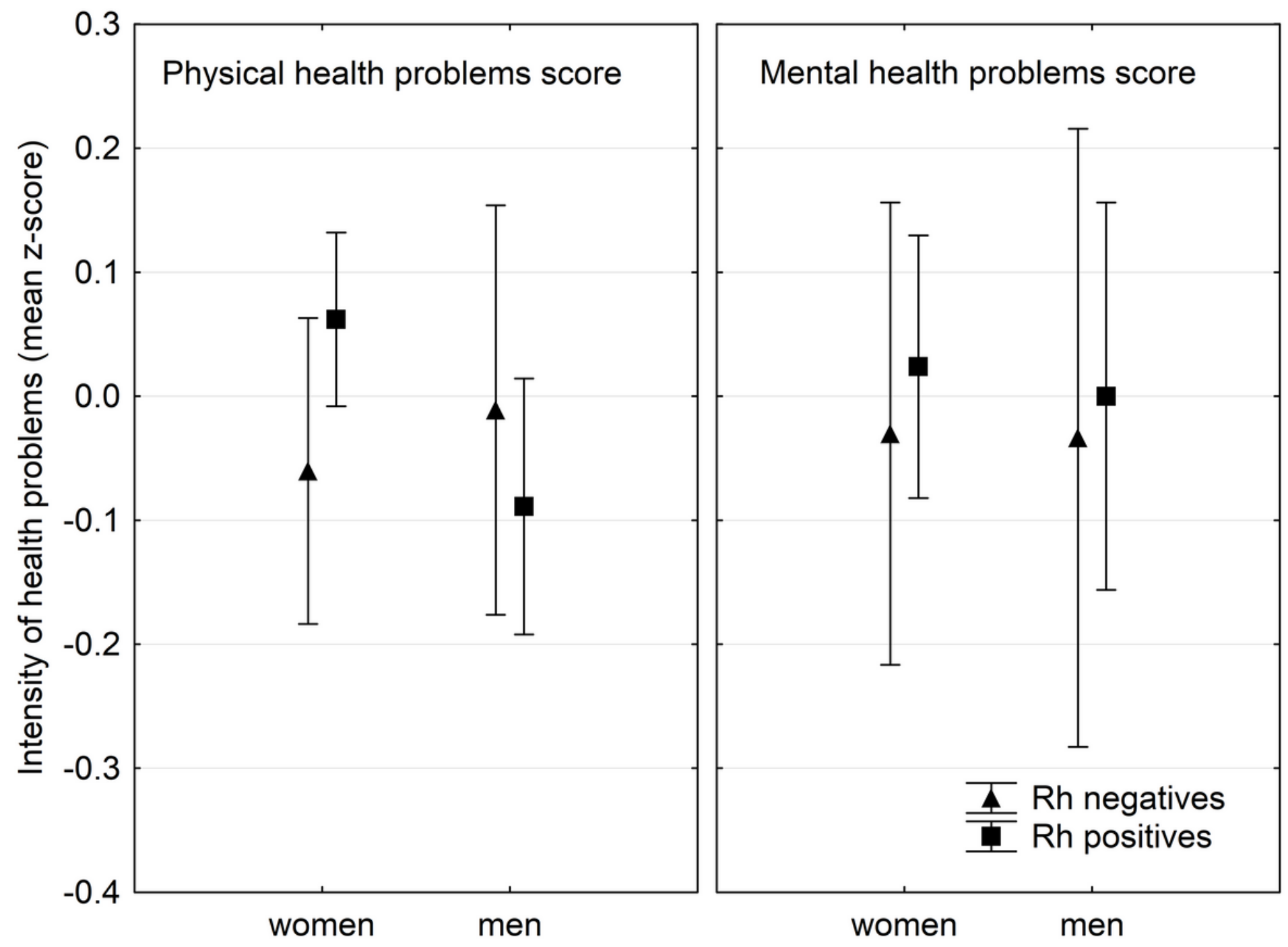

Figure 2

Effects of Rh phenotype and sex on physical and mental health 